http://dx.doi.org/10.30681/23588403v13i0209

\title{
AS MÃES NA LITERATURA: ATUALIDADE DE UM TEMA
}

Data de recebimento: $08 / 03 / 2020$

Aceite: 06/05/2020

Gabriela Dal Bosco SITTA (UFRGS) ${ }^{1}$

\begin{abstract}
Resumo: este trabalho trata da problematização da maternidade na literatura contemporânea a partir da análise de obras nacionais e estrangeiras sobre o tema, como Com armas sonolentas, da brasileira Carola Saavedra (2018), e A filha perdida, da italiana Elena Ferrante (2006). Nosso intuito é identificar subtemas relacionados a essa temática, investigar as contingências ligadas à sua emergência e indicar abordagens possíveis para a leitura das obras. Para isso, nos valemos de alguns conceitos psicanalíticos (KEHL, 2009, 2016; FREUD, 1974), da historiografia (BADINTER, 1980) e da crítica e da teoria feministas (STEVENS, 2005; MERUANE, 2018), mostrando que a problematização da maternidade na literatura contemporânea insere novos termos e perspectivas na corrente de discursos sobre essa temática, modificando as práticas falantes (KEHL, 2016).
\end{abstract}

Palavras-chave: Maternidade. Literatura contemporânea. Mulher.

Abstract: this work focus on how motherhood is discussed in contemporary literature by analyzing books such as Com armas Sonolentas, by the Brazilian writer Carola Saavedra (2018), and The Lost Daughter, by the Italian author Elena Ferrante (2006). Our aim is to identify sub-themes related to the main subject of motherhood, to explore contingencies linked with the emergency of this topic and to propose some approaches to the books about motherhood. Thus, we use psychanalytic concepts (KEHL, 2009, 2016; FREUD, 1974), historiography (BADINTER, 1980), and feminist critic and theory (STEVENS, 2005; MERUANE, 2018). At the end, we conclude that discussions upon motherhood in contemporary literature insert new terms and perspectives about this subject in social discourse flow, changing speaking practices (KEHL, 2016).

Keywords: Motherhood. Contemporary literature. Women.

\section{Introdução}

Em O prazer do texto, Roland Barthes (2006, p. 46) define o escritor como o sujeito que brinca com o corpo da mãe: "para o glorificar, para o embelezar, ou para o despedaçar, para o levar ao limite daquele que, do corpo, pode ser reconhecido". O que o autor tem em mente, por óbvio, não é a constituição física feminina, seios, quadril, órgãos sexuais; Barthes se refere à língua materna, uma instância que funcionaria como matéria-prima da escritura. É curioso como tal ideia se contrapõe, por exemplo, à teoria psicanalítica, que vincula a linguagem à lei

\footnotetext{
${ }^{1}$ Jornalista e graduanda em Letras pela Universidade Federal do Rio Grande do Sul (UFRGS). Porto Alegre, Brasil. Contato: gabriela.sitta@gmail.com.
} 


\section{Revista de Estudos Acadêmicos de Letras}

simbólica (social), e esta, ao pai. Em uma sociedade historicamente marcada pela prevalência do masculino, o vínculo entre a língua, a linguagem e o feminino ainda assumem, em muitos casos, feições de novidade. É o que acontece, por exemplo, quando o tema da maternidade passa a ocupar as estantes das livrarias.

A figura da mãe tem aparecido e sido problematizada em diversos textos, ficcionais ou não, desde a Antiguidade. Ela está presente, por exemplo, em Medeia, de Eurípedes, que data do século V a.C., e em Emílio, ou da Educação, de Rousseau, escrito no século XVIII. Mas o que chama a atenção nas últimas décadas é que tal figura, além de ter se tornado tema central de diversas obras literárias (ficcionais ou não), aparece agora sob um viés bastante específico. Entram em cena personagens de mães arrependidas e de mães que expõem os percalços da maternidade, tratando da relação complexa com o próprio corpo grávido e das complicações das tarefas relativas aos filhos. Além disso, há diversas autoras escrevendo sobre a decisão de ter ou não filhos, questionando, por exemplo, a valorização social do papel de mãe e a redução da mulher a ele (MERUANE, 2018).

Embora ainda nos 1970 tenham sido publicadas obras cruciais a respeito das questões que circundam a experiência materna - como o livro de memórias Mother knot, da norteamericana Jane Lazarre, de 1976, e As alegrias da maternidade, da nigeriana Buchi Emecheta, de 1979 — nestas primeiras décadas do século XXI, uma onda de títulos sobre o tema têm chegado aos leitores. Destacam-se, por exemplo, Maternidade: um romance, da canadense Sheila Hedi, publicado em 2018, A filha perdida, da italiana Elena Ferrante, de 2006, e Rostos na multidão, da mexicana Valeria Luiselli, de 2011.

Em Rostos na multidão, Luiselli cria uma mãe narradora que, ao mesmo tempo em que cuida de dois filhos pequenos, tenta escrever sobre os anos que passou em Nova Iorque e sobre a sua fascinação por um poeta obscuro. Em dado momento da trama, a personagem conta que parou de amamentar o seu bebê: "Passei cinco dias com os seios vermelhos e muito duros. Mas a ideia de deixar de produzir leite me anima. Não era fácil, nunca é fácil, ser uma pessoa que produz leite" (LUISELLI, 2012, p. 76). Em A filha perdida, de Ferrante, a narradora é mãe de duas filhas já adultas e deixa claro o alívio que sente por não ter mais de tomar conta de ambas: "Senti-me milagrosamente desvinculada, como se um trabalho difícil, enfim concluído, não fosse mais um peso sobre meus ombros" (FERRANTE, 2016, p. 8).

No Brasil, a maternidade aparece em autoras como Carola Saavedra (Com armas sonolentas, de 2018), Eliane Brum (Uma duas, de 2011) e Martha Batalha (A vida invisível de Eurídice Gusmão, de 2016). O trecho a seguir, de Com armas sonolentas, exemplifica as 


\section{Revista de Estudos Acadêmicos de Letras}

reflexões feitas nas obras mencionadas. Nele, uma das personagens centrais do enredo, Anna, faz considerações sobre a sua relação com a filha:

Eu fiz tudo isso: gestei, pari e vesti e alimentei um pedaço de carne, chamado também de "outro ser humano", e limpei sua secreções e excrementos e o coloquei num berço a salvo de intempéries e predadores, eu fiz tudo isso que minha mãe e minha avó e minha bisavó e minha tataravó e minha tataratataravó haviam feito, mas nem por isso tornei-me mãe (SAAVEDRA, 2018, p. 176).

Nesse excerto, está em discussão tanto o amor materno, por séculos considerado instintivo, quanto o legado de cuidados que é transmitido entre as gerações de mães. Na obra de Saavedra, também têm destaque tópicos como o corpo da mãe (afetado ao longo da gravidez), a distinção entre o natural e o socialmente construído em matéria de maternidade, a relação ambivalente entre mães e filhas e os impasses enfrentados por quem não deseja uma prole. Esses aspectos, em maior ou menor grau, também são tratados nas outras obras mencionadas, o que permite defini-los como temas centrais dos textos literários que problematizam a maternidade na contemporaneidade.

Além das obras ficcionais, textos de não ficção sobre o tema têm atraído a atenção das editoras. É o caso de Revolução Laura: reflexões sobre maternidade e resistência, que reúne escritos em que a jornalista Manuela D’Ávila, mais conhecida por sua trajetória política, reflete sobre a experiência de ser mãe. Na introdução do livro, publicado em 2019, a autora se diz "uma mulher que percorreu um país continental, amamentando sua filha e, portanto, construindo uma nova forma de ocupação do espaço político. Uma mulher que pode sair livre porque tem um companheiro com quem deixar a filha" (D’ÁVILA, 2019). Como veremos, a paternidade, por seu lado, também tem sido posta em questão por diferentes escritores.

Parece-nos, assim, que as mães da literatura contemporânea expõem, como mostram os excertos destacados, percepções que até há poucos anos (principalmente no Brasil) chegavam com escassez às páginas dos livros. Hoje, para falar sobre a maternidade, as autoras - que não necessariamente se confundem com as mães — valem-se de um léxico que complexifica os laços parentais e põem em xeque a relação entre o feminino e o âmbito materno. Ora, é necessário prestar atenção quando Luiselli escreve que não "é fácil ser uma pessoa que produz leite" e quando a personagem de Ferrante afirma-se satisfeita em desvincular-se das filhas. Para haver a possibilidade de se dizer tais coisas, naturalmente percorreu-se um caminho longo, tortuoso.

Nas páginas a seguir, nosso intuito é investigar as contingências que levam a essa onda de textos contemporâneos sobre a maternidade, bem como os fatores envolvidos no crescente 


\section{Revista de Estudos Acadêmicos de Letras}

104

interesse pelo tema. Em síntese, procuramos delimitar alguns problemas relacionados à emergência da temática da maternidade na literatura atual e indicar abordagens possíveis para a leitura das obras que têm surgido. Essa empreitada só pode ser levada a cabo a partir da conjugação de diferentes áreas de conhecimento; aqui, levamos em consideração alguns conceitos psicanalíticos, a historiografia e a crítica e a teoria feministas.

\section{A maternidade problematizada: abordagens e análises possíveis}

Adrienne Rich (1981 apud STEVENS, 2005, p. 4), na metade dos anos 1970, insistia que "As mulheres têm sido mães e filhas, mas têm escrito muito pouco sobre esse assunto; a grande maioria das imagens literárias e visuais da maternidade vem até nós filtrada através da consciência masculina, [seja] individual ou coletiva". Foi assim, por meio da "consciência masculina, individual ou coletiva", que duas esposas e mães famosas chegaram — para ficar — no mundo das letras: a francesa Emma Bovary e a russa Anna Kariênina.

Emma e Anna têm muito em comum. Ambas são criações da segunda metade do século XIX e estão insatisfeitas com seu casamento. Madame Bovary, imaginada por Gustave Flaubert, e Anna Kariênina, formulada pela pena de Liev Tolstói, são mulheres na faixa dos 20 anos que perdem o interesse em seus maridos, encontram amantes e, devido ao desenrolar insatisfatório dos seus relacionamentos adúlteros, cometem suicídio. O que nos interessa aqui, em especial, é a relação de ambas as mulheres com seus filhos. Emma é superficial e egoísta, o que se revela em sua relação com a filha durante todo o romance; já Anna era uma mãe devotada antes de trair o marido (MEYER, 1995). Em suma, as personagens se revelam mães condenáveis: aquelas que deixam seus filhos (e seus maridos) em segundo plano a fim de buscar a própria felicidade, o que coloca tanto a configuração familiar patriarcal quanto o modelo de casamento burguês em crise.

O fato de as obras terem sido escritas por intelectuais europeus do século XIX naturalmente deve embasar qualquer interpretação que se possa fazer de Anna Kariênina e Madame Bovary. O que se tem, portanto, são homens escrevendo em uma sociedade em que a figura da mãe ainda possuía contornos bastante específicos, assim como a figura da esposa. Isto é, no contexto oitocentista, os discursos em circulação não eram os femininos. Daí que a esposa insatisfeita e a mãe desinteressada sejam caracterizadas de um ponto de vista masculino. Anna e Emma são condenáveis por serem burguesas e englobarem as contradições e o ridículo de sua classe, mas também por não corresponderem ao que se espera delas enquanto mulheres de sua época. 


\section{Revista de Estudos Acadêmicos de Letras}

Nesse sentido, como destaca Kehl (2016, p. 91), “a tragédia de Emma revela, sobretudo, o aspecto da dificuldade, específica das mulheres de então, em criar discursos que respondessem a suas necessidades expressivas emergentes". Entre tais necessidades, podemos incluir a de discorrer acerca dos dilemas da maternidade e da imposição de amar os filhos. É isso o que nos leva a considerar que, descontadas as imensas discrepâncias contextuais entre a mãe e esposa burguesa do século XIX e a mãe de classe média contemporânea, se escritas por mulheres e destituídas do aspecto culpabilizatório, as descrições das relações entre mães e filhos que aparecem nas obras de Flaubert e Tolstói passariam facilmente por textos do século XXI.

"Se escritas por mulheres": essa condição aponta para um aspecto importante, a constituição de uma voz específica na literatura, o que envolve a possibilidade de as mulheres disseminarem o seu próprio entendimento sobre questões - veja só! — tão femininas. Em 1899, a norte-americana Kate Chopin deu mostras de uma escrita que se debruça sobre tais questões ao publicar The Awakening, que aborda o adultério e a maternidade do ponto de vista feminino (FOLTRAN, 2006). Contudo, só muito recentemente um contingente maior de mulheres começou a escrever sobre a maternidade, e só mais recentemente ainda tal escrita se propôs a desvelar determinados aspectos da experiência materna, a exemplo do arrependimento, das dores e da perda de autonomia e liberdade. Daí a necessidade de se prestar atenção ao que as mulheres têm dito sobre esse tema, ao modo como se configuram os discursos, às insatisfações que eles revelam.

A novidade nisso tudo não está no que se diz, já que há muito as dores do parto e da amamentação, por exemplo, vêm sendo narradas a qualquer um que se interesse em ouvir. Como formula Michel Foucault (2009, p. 26), “O novo não está no que é dito, mas no acontecimento de sua volta". Isto é: o que nos interessa aqui é o retorno do tema da experiência materna à literatura enquanto um acontecimento singular. A novidade, portanto, é a circulação de textos literários que problematizam a maternidade, o que leva à disseminação de uma abordagem específica sobre a experiência materna, como estamos vendo.

A partir da consciência de que a maternidade implica os mais diferentes conflitos, questiona-se agora se ela é capaz de proporcionar a tão ansiada completude feminina. Para tratar de tal completude, recorrentemente vinculada à experiência materna, uma abordagem psicanalítica pode ser fecunda. Para Freud (1974), o desenvolvimento psicossexual das crianças passa por duas fases: a pré-edipiana, em que o bebê está extremamente ligado à mãe, como se constituísse com ela uma unidade; e a fase do complexo de Édipo, dividida em duas etapas: "Se no curso normal do primeiro tempo do Édipo a criança está identificada simbolicamente com o 


\section{Revista de Estudos Acadêmicos de Letras}

objeto que falta à mãe e seu desejo está sujeito à demanda dela, no segundo tempo o pai entra como mediador do desejo da mãe" (KEHL, 2009, p. 245). É nesse segundo momento que, na perspectiva lacaniana, se dá a castração: tanto se desfaz a unidade do bebê com a mãe quanto a criança se dá conta de que não é suficiente para satisfazer plenamente a sua progenitora (já que o pai também a demanda e é desejado por ela). Assim, “o que se introduz nesse momento para a criança é a dimensão da falta de objeto, já que a entrada do pai como aquele que detém o objeto para o qual se volta o desejo materno vem interditar a satisfação do impulso" (KEHL, 2009, p. 245, grifo nosso).

A falta, em psicanálise, é o resultado da castração. Para Freud (1974, p. 263), esse processo envolve a descoberta, pelo menino, dos órgãos genitais femininos, o que produz nele a angústia da castração: "[isso] impõe ao menino a transformação do seu complexo de Édipo e conduz à criação de seu superego [instância psíquica que engloba a dimensão moral e as 'leis' que vão regular o comportamento do sujeito], iniciando assim todos os processos que se destinam a fazer o indivíduo encontrar lugar na comunidade cultural". No caso da menina, a angústia da castração surge quando ela se depara com o órgão do menino e percebe que, nela, algo falta. Para Lacan (apud KEHL, 2009), a castração, ou seja, a constatação da impossibilidade de completude, ocorre mais cedo, com a interdição, mediada pelo pai, da unidade do bebê com a mãe. No processo de uma análise, busca-se simbolizar tal castração, de modo que o sujeito perceba que a falta é constituinte do ser, que a possibilidade de completude não existe - nem para homens, nem para mulheres.

Com a constatação da falta (em si mesmo e no outro), aporta no sujeito o desejo, que é o que, em última instância, leva-o a agir individual e socialmente. Contudo, não há um objeto preciso capaz de preencher o espaço da falta (o ser é, afinal, sempre incompleto). Como sintetiza Kehl (2009, p. 90), “o desejo não tem objeto que o satisfaça; é puro impulso em busca do reencontro impossível com um objeto perdido". Ao significante de tal objeto perdido, ou seja, àquilo que, ao longo da vida, o sujeito busca, Lacan (apud KEHL, 2009) chama de "falo".

$\mathrm{Na}$ experiência da maternidade, o falo é um elemento essencial:

desde a gestação, a relação que se estabelece entre a mãe e o recém-nascido já não é natural. O que a mãe visa, ao revestir seu bebê de amor e de cuidados, é sempre o falo - significante de um objeto que (desde sempre) lhe falta. Isso não significa que o bebê seja o objeto do desejo da mãe: ele é o significante desse objeto (KEHL, 2009, p. 199).

Logo, a maternidade tem a ver com a unidade e a divisão da mãe por meio da prole, a noção (sempre sustentada por uma fantasia, como nos mostra a psicanálise) de que um filho proporciona completude. Foi essa a perspectiva predominante entre o século XVIII e meados 


\section{Revista de Estudos Acadêmicos de Letras}

do século XX, quando houve a explosão da segunda onda do feminismo. ${ }^{2}$ No século XVIII, com Rousseau, ganha destaque a mãe enquanto figura benéfica, acolhedora, doce, capaz de abdicar de tudo em favor dos filhos (BADINTER, 1980). É essa a mulher cuja natureza remete à maternidade, a mesma que, em Freud (1974, p. 264), atingirá a "atitude feminina normal final". Depois da metade do século XX, entra em cena o outro lado da moeda: em vez da completude, os filhos inscrevem na mulher a falta: de liberdade, de autonomia, de tempo, de identificação com o próprio corpo, de possibilidades de deslocamento, etc. É no coro de vozes não tão satisfeitas com a autoanulação em prol dos filhos que se enquadram discursos como os das narradoras mães de Ferrante, Luiselli e Saavedra. São discursos muitas vezes raivosos, inconformados.

Nos últimos anos, além das mães, também os pais personagens e/ou narradores têm se multiplicado, muitos deles dedicados a dissertar a respeito da sua relação com os filhos de forma não muito decorosa. Esses pais, ainda que tenham chegado um tanto atrasados à seara dos cuidados domésticos com a prole, não tardam a explicitar as suas frustrações. O escritor norueguês Karl Ove Knausgård, em A morte do pai, escreve diversas páginas a respeito da sua convivência com os filhos e da relação que teve com o próprio pai. Ele confessa, por exemplo, o seguinte:

nenhuma das minhas experiências anteriores me preveniu da invasão de privacidade que ter filhos implica. A intimidade extrema que temos com eles, a maneira como nosso temperamento e humor, por assim dizer, se mesclam aos deles, tanto que nossos defeitos deixam de ser particulares, não podem mais ser encobertos, mas de certo modo assumem uma forma exterior e se voltam contra nós (KNAUSGÅRD, 2015).

Outro escritor contemporâneo que escreve a respeito da paternidade é o argentino Pedro Mairal. Em La uruguaya, o narrador-protagonista, que se dirige à esposa, apelida seu filho de “anão bêbado". Em síntese, a obra gira em torno de um homem cujo casamento está em crise; entre os fatores que complexificam a situação, inclui-se a criança. Em dado momento, o narrador afirma: "Vos sabés que lo adoro a mi hijo. Lo quiero más que a nadie en el mundo. Pero a vezes me agota, no tanto él sino mi constante preocupación por él. A veces pienso que

\footnotetext{
${ }^{2}$ Costuma-se apresentar o movimento feminista dividido em três grandes ondas, que abrangem tanto o âmbito teórico quanto o político e o cultural. A primeira delas se estende do final do século XIX ao início do século XX, incluindo, portanto, textos como os da escritora inglesa Virgínia Woolf, autora de Um teto todo seu, e o movimento das sufragistas, que defendiam o voto feminino. A segunda onda surge com o lançamento, em 1949, de O segundo sexo, da francesa Simone de Beauvoir. Esse período se estende até o final do século XX. Por volta de 1990, emerge a terceira onda, que amplia as reivindicações e a abrangência do movimento, incluindo a teoria queer, as reflexões sobre o racismo, o pós-colonialismo e a teoria crítica, por exemplo (ZINANI, 2011).
} 


\section{Revista de Estudos Acadêmicos de Letras}

no tendría que haber tenido un hijo a esta edad" (MAIRAL, 2018, p. 50-51). Em outro trecho, lê-se o seguinte:

Mi hijo. Ese enano borracho. Porque era así a veces, como cuidar un enano borracho que se pone emocional, llora, no le entendés lo que te dice, lo tenés que estar atajando, lo tenés que levantar porque no quiere caminar, hace un desastre en restorán, tira cosas, grita, se durme en cualquier lado, lo llevás a la casa, tratás de bañarlo, se cae, se hace un chichón, empuja muebles, se duerme, vomita a las cuatro de la mañana (MAIRAL, 2018, p. 50).

Além de levá-lo ao riso com uma descrição tão sincera e precisa, Mairal provoca o leitor a repensar o que significa ser pai. O fato de sua franqueza parecer inusitada deixa entrever que grande parte dos discursos correntes que põem de lado algumas agruras da paternidade tem pontos-cegos. Ademais, assim como no caso de Ferrante, Luiselli e Knausgård, destaca-se aqui a noção de que ter filhos é abrir mão de uma parte de si. Em alguma medida, é como se o círculo que envolve pais e filhos tivesse dimensões limitadas: para que o outro que nasce possa se assentar com conforto, o eu que dá a vida a ele precisa abrir espaço, encolher-se. Retorna, aqui, a noção da castração: o filho é o responsável por inserir a falta no pai e na mãe. Contudo, a falta é constituinte do ser; como vimos, ela se insere ainda nas fases primárias do seu desenvolvimento psicossexual. Nesse sentido, é possível encarar o modo com que as mães (e agora os pais) lidam com a instituição filial como um indício de que a castração — a constatação da incompletude em si mesmo e no outro — vem sendo negada pelos sujeitos.

Do século XVII até meados do século XX, os discursos circulantes defendiam que a mulher só se completava com um filho; a prole era a promessa de restituição do $e u$, de realização (BADINTER, 1980). No caso dos homens, os filhos representavam a perpetuação e, no âmbito social, político e econômico, a possibilidade de concretização de um projeto de sociedade e civilização. Como afirma Badinter (1980, p. 121), nesse período se dá a "exaltação do amor materno como um valor ao mesmo tempo natural e social, favorável à espécie e à sociedade”. Por outro lado, no discurso contemporâneo sobre a maternidade enquanto perda de liberdade, a negação da falta inerente ao ser se dá de outro modo: não é o eu que é, desde sempre, incompleto; o que o torna assim é o outro, o filho, que rouba o seu espaço, retira dele a liberdade e minimiza o seu arbítrio para guiar a própria vida.

Enquanto no primeiro caso a negação da falta/castração pode ser explicada pelo ideário iluminista, que não põe em xeque as capacidades do homem nem questiona os rumos de uma humanidade triunfante sempre em direção ao progresso, no segundo caso, a explicação passa pela influência do capitalismo tardio e dos imperativos à felicidade que pululam nos tempos atuais (BADINTER, 1980; KEHL, 2009). Como analisa Kehl (2009), a falta que caracteriza o 


\section{Revista de Estudos Acadêmicos de Letras}

sujeito implica a capacidade de ele lidar com as frustrações que marcam a sua vida e de relacionar-se com o outro (nos âmbitos pessoal e público). Contudo, em especial a partir do final do século XX, a associação entre sistema capitalista e neoliberalismo vem promovendo ofertas infinitas que prometem tapar o buraco da falta do sujeito. São produtos e serviços que se afirmam capazes de fazer o sujeito realizar, construir, empoderar-se, embelezar-se, empreender, etc. Em síntese, multiplicam-se "sociedades regidas pelo imperativo da felicidade, da predisposição permanente a divertir-se e a gozar" (KEHL, 2009, p. 194), o que, em muitos casos, acentua ou cria quadros de depressão, por exemplo, na medida em que um excesso de gozo atenta contra o desejo, não deixa que a falta mova o sujeito (KEHL, 2009).

No caso dos pais, como os narradores de Knausgård e Mairal, Kehl (2009) toca em um aspecto instigante. Para a autora, nestes tempos marcados pelo neoliberalismo, pelo imperativo do consumo e da felicidade, pela positividade e pela prevalência do individual sobre o coletivo, a figura do pai vem perdendo a sua relevância. Nessa perspectiva, a sua autoridade é substituída pela lei do mercado, pela ordem capitalista. Não é fácil para um pai sustentar seu lugar diante dos imperativos de gozo e de soberania do indivíduo que caracterizam o momento atual das sociedades capitalistas. Afinal, o que é um pai? Freud foi sensível a essa questão, ao repetir o dito popular que estabelece o pai como incerto em comparação com a certeza biológica da maternidade (KEHL, 2009).

Por sua vez, Badinter (1980) explica que, na estrutura familiar, o pai vem sendo obscurecido desde o final do século XVIII, quando os discursos sobre a importância do empenho da mãe na criação dos filhos passaram a circular mais. Somam-se a esses fatores a ainda recente inserção das mulheres em diferentes setores sociais e as novas configurações familiares. Não é de surpreender, portanto, que os homens, como as mulheres, tenham tomado para si a tarefa de, por meio de diferentes tipos de texto, refletir sobre o que significa ser pai ou filho a partir de uma perspectiva mais franca.

Quanto às autoras, depois de séculos de predomínio de uma concepção idealizada da maternidade, elas expõem agora as dificuldades da tarefa materna, como se deliberadamente provocassem a queda do "anjo do lar” descrito por Virgínia Woolf (2014) em Um teto todo seu. Nesse sentido, talvez valha a pena deter-nos por mais algum tempo nesta questão: por que agora é possível expor as facetas conflituosas da experiência materna?

Além das circunstâncias já mencionadas - conquistas sociais das mulheres em diversos âmbitos, explosão feminista, etc. —, dois outros ângulos de análise nos parecem interessantes. Cristina Stevens (2005) relaciona a fala das mulheres a respeito da maternidade 


\section{Revista de Estudos Acadêmicos de Letras}

à liberação de algo que ficara contido na abordagem freudiana sobre a relação entre mãe e filho. Como já mencionamos, para Freud, o desenvolvimento psicossexual das crianças passa pela fase pré-edipiana e pela fase do complexo de Édipo. Stevens (2005) afirma que Freud não se dedica a investigar a fundo a fase pré-edipiana. O psicanalista alega que "Tudo na esfera dessa primeira ligação com a mãe [...] [parece] tão esmaecido pelo tempo e tão obscuro e quase impossível de revivificar - que era como se houvesse sucumbido a uma repressão especialmente inexorável" (FREUD, 1974, p. 260-261). Assim, enquanto a fase pré-edipiana seria de domínio exclusivamente materno, no complexo de Édipo, a presença do pai se imporia e seria determinante; afinal, é o pai, na concepção psicanalítica, o responsável por instituir a lei, a proibição, o que passa pela linguagem e leva à formação do supereu (ou superego).

Em contraponto ao silêncio de Freud acerca da fase pré-edípica, Stevens (2005) menciona o trabalho de Cixous, Irigaray e Kristeva, que teriam

enfatizado a fase pré-edipiana, quando os esforços cognitivos da criança são quase que exclusivamente direcionados para a mãe. Para elas, a fase préedipiana - uma "presença ausente" — subverte a fase edipiana, ao revelar o substrato matriarcal de todo desenvolvimento psíquico (STEVENS, 2005, p. 6-7).

É a partir daí que Stevens (2005), com base em Hélène Cixous, desenvolve a ideia de que o discurso das mulheres sobre a maternidade funciona como uma transgressão, contrariando o pressuposto freudiano de que a fase pré-edipiana não possui história nem narrativa. Dessa forma, tal fase "só pode ser alcançada retrospectivamente (depois de abandonada), não através de processos conscientes ou da memória, mas através de projeções e fantasias" (STEVENS, 2005, p. 7); portanto, também a partir da literatura.

É necessário, todavia, problematizar a posição defendida por Stevens (2005). Ao discorrer sobre a teoria psicanalítica, ela não considera que a linguagem é apresentada ao bebê primeiro pela mãe. Como afirma Kehl (2009), o Nome-do-Pai, ou seja, a dimensão simbólica da lei, se inscreve por meio do discurso da mãe. Portanto, embora não tenha a posição de destaque que Stevens (2005) gostaria de conferir a ela, a mãe, ao menos para Lacan (que formula o conceito de Nome-do-Pai), tem, sim, poder de fala, ainda que para mediar a relação do bebê com o pai — isto é, a lei simbólica. Para além disso, Stevens (2005) parece confundir a perspectiva da mãe com a do bebê. Isso fica claro quando ela afirma que a fase pré-edipiana só pode ser alcançada de forma retrospectiva: quem precisaria retroceder seria o bebê, não a mãe, cujo desenvolvimento psicossexual, supõe-se, esteja já finalizado no momento em que dá à luz. Isso, contudo, não anula de todo o interesse da perspectiva desenvolvida pela autora. 


\section{Revista de Estudos Acadêmicos de Letras}

Quando afirma que, “para a Psicanálise, a repressão da mãe situa-se precisamente no estágio a partir do qual se origina a linguagem, da mesma forma que a narrativa se estrutura muitas vezes a partir da eliminação da figura da mãe" (STEVENS, 2005, p. 11), ela se vale de um argumento que funciona, se não em definitivo, ao menos parcial e metaforicamente. É, afinal, verdadeiro que na teoria psicanalítica a dimensão social, em especial com a inscrição do superego, fica a cargo da figura paterna, enquanto a mãe, mais ligada ao gozo da fase préedipiana, tem sua figura restrita a um ambiente doméstico, em que os corpos se conjugam, ficam próximos. Ao postular que "a narrativa se estrutura muitas vezes a partir da eliminação da figura da mãe", vinculando tal eliminação ao obscurecimento da fase pré-edipiana, Stevens (2005) deixa claro o que indicamos mais acima a respeito da predominância histórica de narrativas sobre maternidade escritas por homens, embora seja necessário pontuar que, ao contrário do que ela diz, a mãe como personagem é uma constante na história da literatura - Medeia, personagem que dá nome à tragédia de Eurípedes, já coloca em questão a maternidade quando mata os próprios filhos a fim de atingir Jasão. Nesse mesmo sentido, Rich (1981 apud STEVENS, 2005, p. 4) afirma:

Assim que uma mulher sabe que uma criança está crescendo dentro do seu corpo, ela encontra-se sob o poder de teorias, ideais, arquétipos, descrições sobre sua nova existência; quase nenhuma das quais desenvolvidas por outras mulheres (embora outras mulheres possam transmiti-las); todas essas ideias flutuam invisivelmente ao redor dela desde que ela se percebeu mulher pela primeira vez, e como tal, uma mãe em potencial.

Portanto, a ideia que Stevens (2005) nos ajuda a formular é a seguinte: um dos fatores que possibilitam a problematização da maternidade na ficção contemporânea é a valorização do ponto de vista da mãe a respeito da criança, situação devedora das discussões feministas desenvolvidas especialmente a partir dos anos 1950. Mas tal ponto de vista, diferentemente do que a autora indica, não se origina a partir de uma abordagem retrospectiva, que só faria sentido se fosse o filho, e não a mãe/mulher, o narrador. O que promove esse ponto de vista é a desnaturalização do vínculo entre o bebê e a mãe, vínculo este que, para Freud, é fundamental na fase pré-edipiana, dado que, segundo o psicanalista, a criança perece sem os cuidados e o seio maternos. Se há qualquer tipo de retrospectiva, é só na medida em que as mães narradoras retomam os pressupostos freudianos a respeito de tal fase para dizer que "não é bem assim". Um dos textos seminais desse discurso sobre a maternidade é Um amor conquistado: o mito do amor materno, publicado em 1980 pela francesa Elisabeth Badinter, que já mencionamos acima. Nesse livro, Badinter desconstrói a noção de que há algo de incondicional ou natural no 


\section{Revista de Estudos Acadêmicos de Letras}

amor de uma mãe por seu filho por meio de uma reconstituição historiográfica da figura da mãe materna na sociedade burguesa dos séculos XVIII e XIX.

Outro ângulo de análise que nos parece fecundo para explicar a recorrência das mães "problematizadas" na ficção das últimas décadas é aquele que considera as mães superdedicadas pós-modernas, semelhantes às mães pré-feminismos. A dedicação dessas mães contemporâneas se explica, por um lado, pela crise da paternidade, que já apontamos. Por outro lado, o cuidado com os filhos passou a integrar, na sociedade capitalista contemporânea, o rol de demandas que exigem produtividade, desempenho, criatividade, cuidado com o meio ambiente e mais uma lista infinita de exigências. À mãe superdedicada, Lina Meruane (2018) intitula "mãe-total" ou "supermãe".

Precisamente porque está bem cotada na dinâmica social - em especial, como fica subentendido no texto de Meruane (2018), entre as classes médias - , a maternidade é alvo de comentários os mais diversos, que vão dos mais positivos (os discursos sobre a completude obtida apenas por meio da experiência materna, por exemplo) aos mais pessimistas e sinceros (como os contidos nos textos literários citados anteriormente, ou como a afirmação de que o antiquado dever de ser mãe não sai de cena tão facilmente e de que se vive agora o império dos filhos). No ensaio Contra os filhos, Meruane (2018) aponta para as incongruências das mães contemporâneas que, herdeiras das conquistas feministas do século XX, engendram regressos em avanços que, por alguns anos, pareceram tão consolidados. No entanto, esses termos "regresso" e "avanço" - não seriam os mais adequados para dar conta da situação, o que a própria autora demonstra perceber em seu texto.

Meruane (2018) argumenta que, ao contrário do que parece, as mulheres não se destituíram de todo da antiga arenga que vincula o corpo feminino essencialmente à reprodução, entendida como única possibilidade de autorrealização e completude. Para ela, não há "nada novo", predomina ainda "o amor incondicional da mãe como sinônimo de um trabalho que não tem retribuição nem conhece descanso" (MERUANE, 2018, p. 136). Nestes tempos pósmodernos, não obstante, tal arenga vem revestida de termos mais atrativos, é claro. Sobem ao palco agora mães militantes, atarefadas com demandas que vão desde as fraldas ecológicas até o futuro sucesso profissional dos filhos - isso exemplifica o que Kehl (2009) diz a respeito da minimização da figura paterna, que dá espaço à lei do mercado, à ordem capitalista. Daí que Meruane (2018, p. 118-119) afirme o seguinte:

A história das mães é a de recorrências e repetições, o aparente progressismo de corte ecológico não passa do reaparecimento, em versão new age, do mandato angélico ou medonho ou místico-feminino, é o culto renovado à 


\section{Revista de Estudos Acadêmicos de Letras}

maternidade intensiva e absoluta que funciona, agora, além disso, como um marcador social. [...] a obrigação atual da mãe é oferecer a seus filhos vantagens comparativas num mundo cada vez mais competitivo.

A mãe pós-moderna é, para a autora chilena, a "esposa-amante", a "mãe-esforçada-eresponsável", aquela "disposta a dar o peito enquanto trabalha", a "mulher-que-trabalha-desucesso", a "mãe-máquina", a "mãe-ecológica" (MERUANE, 2018, p. 124). É como se, em tempos de capitalismo tardio, as demandas por produção e consumo que movem a máquina social passassem a integrar também (e por que não haveria de ser?) o cotidiano da mãe, que vê as suas funções se multiplicarem enquanto a sua habilidade de lidar com as exigências que a rodeiam ditam se ela é a progenitora (e a mulher) que o mundo espera que seja.

No ímpeto de dar conta das reivindicações que a cercam por todos os lados, a mãe pósmoderna corre contra o tempo, atenta ao imediatismo das redes sociais, empenhada em preparar a prole para se dar bem nas acirradas disputas por emprego, reconhecimento social e, claro, felicidade, o imperativo máximo dos anos 2000. Fica de lado, nisso tudo, afirma Meruane (2018), algo que seria essencial: algum tipo de consciência política. Seguindo o irreprimível fluxo do mundo atual, a mãe se aliena. Contudo, para mudar a situação, amenizar as exigências que recaem sobre a supermãe, não há alternativa além de ela assumir o lugar daquela que reivindica. Afinal, "Foram sempre as mulheres que brigaram por sua causa e conseguiram mudanças liberadoras (quase) sem a cumplicidade de seus companheiros ou de seus familiares [...] Foram as mulheres que tiveram que exigir proteção social e outros benefícios do Estado" (MERUANE, 2018, p. 137).

Quando fala em consciência política, Meruane (2019) não encara como ação política a tarefa que as mães se propõem a realizar ao serem, por exemplo, política e ecologicamente corretas na educação dos filhos. O que ela tem em mente é uma consciência a respeito dos próprios direitos, o que levaria as mães a reivindicar "políticas públicas que as levem a sério e valorizem sua contribuição em dinheiro vivo". Entre os exemplos da ineficiência do Estado, Meruane (2018) menciona os empecilhos que mulheres grávidas encontram para se colocar no mercado de trabalho e o fato de que a maioria dos governos cede "a gestão da maternidade à empresa privada regida por homens que não cuidam de filhos" (MERUANE, 2018, p. 138). Naturalmente, o que a autora pontua são circunstância relevantes, que merecem atenção. Contudo, em sua análise, ela não se interessa muito pela subjetividade das mães contemporâneas sobre as quais escreve - essas mulheres superdedicadas, atarefadas e guiadas pela lei do mercado. 


\section{Revista de Estudos Acadêmicos de Letras}

Se retomarmos a perspectiva psicanalítica nesse ponto, podemos inferir que as mães de que fala Meruane (2018) são sujeitos que, como grande parte dos indivíduos que buscam atender às reivindicações do mundo atual, passam por conflitos complexos, grande parte deles relacionados à dificuldade de simbolizar a falta: logo, busca-se por todos os lados — nos filhos, no entretenimento, nos automóveis, nas redes sociais - a parte que falta e que é, já vimos, inapreensível. Diante desse cenário, há certo conforto em encontrar vozes como as de Ferrante, Luiselli e Saavedra, que, frente às demandas da maternidade, ousam se mostrar insatisfeitas, extenuadas, ainda (e ainda bem) incompletas.

A mãe que aparece na ficção contemporânea sobre a qual nos debruçamos aqui se atreve a discorrer a respeito de assuntos que por muito tempo permaneceram velados devido à valorização de um ideário materno ao qual não correspondem insatisfações e arrependimentos, mas somente amor incondicional, masoquismo e doçura (BADINTER, 1980). Esse é o modelo de mãe que aparece em textos como o de Saavedra, o de Luiselli e o de Ferrante. Por outro lado, as reflexões empreendidas aqui indicam a persistência de determinados pressupostos a respeito da experiência materna. É o que Meruane (2018) mostra, por exemplo, quando descreve as supermães pós-modernas, comprometidas em abdicar de si mesmas em favor dos filhos e do reconhecimento social que o cuidado ilimitado com a prole lhes oferece.

O mais interessante nisso tudo - e que a psicanálise nos ajuda a compreender — é o papel da narrativa e da fala na assimilação e na elaboração de questões tão herméticas quanto as que giram em torno da maternidade. Kehl (2016, p. 20), ao abordar a distinção saussuriana entre língua, linguagem e fala, destaca a relevância desta última: é por meio da fala que o sujeito pode fazer "um furo no muro da linguagem", expressando algo que ainda não está inscrito na língua.

A direção de uma cura, na expressão de Lacan, passa não por uma modificação da estrutura da linguagem que o sujeito habita, mas certamente passa por uma modificação de suas práticas falantes. Dominar (relativamente) nossas práticas linguageiras, em vez de sermos inteiramente alienados a elas, eis uma possibilidade de cura vislumbrada pela psicanálise (KEHL, 2016, p. 24).

Inserindo novos termos e perspectivas na corrente de discursos sobre a maternidade, as escritoras que discorrem a respeito desse tema realizam a modificação das práticas falantes de que trata Kehl (2016). Se, como vimos, os textos sobre a maternidade por muito tempo se restringiram a um léxico bem comportado e à descrição de sentimentos irrepreensíveis, agora circulam outros pontos de vista. 


\section{REFERÊNCIAS}

BADINTER, Elisabeth. Um amor conquistado: o mito do amor materno. São Paulo: Círculo do Livro, 1980.

BARTHES, Roland. O prazer do texto. São Paulo: Perspectiva, 2006.

BUTLER, J. Problemas de gênero: feminismo e subversão da identidade. Tradução de Renato Aguiar. Rio de janeiro: Civilização Brasileira, 2003.

D’ÁVILA, Manuela. Revolução Laura: reflexões sobre maternidade e resistência. Caxias do Sul: Editora Belas Letras, 2019. E-book.

EURÍPEDES. Medeia. Disponível em: https://artedramaticacep.files.wordpress.com/2015/07/medeia.pdf. Acesso em: 3 out. 2019. FERRANTE, Elena. A filha perdida. Rio de Janeiro: Intrínseca, 2016.

FLAUBERT, Gustave. Madame Bovary. São Paulo: Companhia das Letras, 2011.

FOLTRAN, Carmen Lúcia. Forma literária e formações sociais em The Awakening de Kate Chopin. 2006, 86 f. Dissertação (Mestrado em Letras) - Faculdade de Filosofia, Letras e Ciências Humanas, Universidade de São Paulo. Disponível em: https://www.teses.usp.br/teses/disponiveis/8/8147/tde-28012008-

113646/publico/DISSERTACAO_CARMEM_LUCIA_FOLTRAN.pdf. Acesso em: 8 mar. 2020.

FOUCAULT, Michel. A ordem do discurso: aula inaugural no Collège de France, pronunciada em 2 de dezembro de 1970. São Paulo: Edições Loyola, 2009.

FREUD, Sigmund. Sexualidade feminina. In: Edição standard brasileira das obras psicológicas completas de Sigmund Freud. Vol. XXI. Rio de Janeiro: Imago Editora, 1974, p. 259-279.

KEHL, Maria Rita. Deslocamentos do feminino. São Paulo: Boitempo, 2016.

KEHL, Maria Rita. O tempo e o cão: a atualidade das depressões. São Paulo: Boitempo, 2009.

KNAUSGÅRD, Karl Ove. A morte do pai. São Paulo: Companhia das Letras, 2015. Ebook.

LUISELLI, Valeria. Rostos na Multidão. Rio de Janeiro: Objetiva, 2012.

MAIRAL, Pedro. La uruguaya. Montevidéu: Editorial Planeta S.A., 2018.

MERUANE, Lina. Contra os filhos. São Paulo: Todavia, 2018. 


\section{Revista de Estudos Acadêmicos de Letras}

MEYER, Pricilla. Anna Karenina: Tolstoy's Polemic with Madame Bovary. Russian

Review, 54.2, 1995, p. 243-259. Disponível em: https://pdfs.semanticscholar.org/dbfa/9a69c11218995637d5e249380a6617e23e10.pdf.

Acesso em: 22 ago. 2019.

ROUSSEAU, Jean-Jacques. Emílio ou da Educação. São Paulo, Rio de Janeiro: Difel. Ebook. Disponível em: http://www.ensinarfilosofia.com.br/wpcontent/uploads/2017/03/Rousseau-Emilio-Ou-Da-Educacao.pdf. Acesso em: 8 nov. 2019. SAAVEDRA, Carola. Com armas sonolentas. São Paulo: Companhia das Letras, 2018. STEVENS, Cristina. Ressignificando a Maternidade: Psicanálise e Literatura. Revista Gênero. Disponível em: http://www.revistagenero.uff.br/index.php/revistagenero/article/view/385/289. Acesso em: 21 ago. 2019.

TOLSTÓI, Liev. Anna Kariênina. São Paulo: Companhia das Letras, 2017.

WOOLF, Virgínia. Um teto todo seu. São Paulo: Tordesilhas, 2014.

ZINANI, C. J. A. Crítica feminista: uma contribuição para a história da literatura. In: IX Seminário Internacional de História da Literatura, 2012, Porto Alegre. Anais [...]. Seminário Internacional de História da Literatura. Porto Alegre: Edipucrs, 2011. p. 407-415. 